\title{
Electrochemical study of the stability of ferrates(VI) in low temperature molten hydroxide
}

\author{
Kamil Kerekeš, Katarína Švaňová, Ján Híveš, Miroslav Gál \\ Institute of Inorganic Chemistry, Technology and Materials, Faculty of Chemical and Food Technology, \\ Slovak University of Technology in Bratislava, Radlinského 9, 81237 Bratislava, Slovakia \\ miroslav.gal@stuba.sk
}

\begin{abstract}
During last decades interest in ferrates(VI) has increased significantly. On one hand they serve as strong, non-toxic oxidants without harmful by-products and, on the other hand, as an efficient coagulant in both drinking and waste water treatment technology. In this work we focused on the electrochemical preparation of ferrate (VI) salts in eutectic low temperature molten sodium hydroxide - water mixture using pure iron anodes. Some information on the stability and kinetics of decomposition of sodium ferrate(VI) prepared by molten-system electrolysis is discussed. An assumption that electrochemically prepared ferrate(VI) in molten hydroxide media are stable enough to be used especially in the field of waste water treatment was confirmed by our observation.
\end{abstract}

Keywords: electrolysis, ferrates, melts, stability

\section{Introduction}

The most common oxidation states in which iron is usually found are $\mathrm{Fe}(\mathrm{II})$ and $\mathrm{Fe}(\mathrm{III})$. Other, rare oxidation states, e.g. ferrate(VI) $\left[\mathrm{Fe}^{\mathrm{VI}} \mathrm{O}_{4}\right]^{2-}$, have been also detected (Macova et al. 2009). One of the most potentially important application of ferrates(VI) is closely connected with both drinking water and wastewater treatment. The main advantage of ferrates(VI) is their high oxidation potential that allows the decomposition of even very stable inorganic, organic and microbiological contaminants. In most cases, ferrates(VI) provides a complete degradation of the pollutant without harmless by-products (Licht et al. 2005). A key factor for ferrate(VI) utilization for water treatment is a product of the ferrate (VI) reduction - ferric hydroxide. $\mathrm{Fe}(\mathrm{OH})_{3}$ does not burden the environment, it is non-toxic and it is also an excellent coagulant and flocculent (Jiang and Lloyd 2002, Jiang and Wang 2003, Lee et al. 2003, Sharma et al. 2005).

According to the literature data, the oldest information about ferrates(VI) is dated back to 1702 (Macova et al. 2009). Electrochemical dissolution of $\mathrm{Fe}$ in various alkaline media has been investigated by several research groups for decades. It can be summarized that in alkaline solutions iron can be electrochemically dissolved as ferrous(II), ferric(III) and finally ferrate(VI) species depending on the electrode potential, both solution and anode composition as well as the temperature (Armstrong and Baurhoo 1972, MacDonald and Roberts 1978, Serebrennikova et al. 2009, Zhang and Park 1994, Denvir and Pletcher 1996, Macova and Bouzek
2011, Macova and Bouzek 2012, Macova et al. 2010, Bouzek et al. 1999, Hives et al. 2008, Pick 1901, Lapicque and Valentin 2002, He et al. 2005). It was also found that the current yield increased with an electrolyte concentration and composition, temperature, as well as with iron electrode composition (Serebrennikova et al. 2009). Grube et al. utilized direct current (DC) with a superimposed alternating current (AC) in order to increase a reaction yield (Grube and Gmelin 1920).

Several attempts to describe the reaction mechanism of ferrate(VI) formation during electrochemical treatment were made (Beck et al. 1985, Bouzek et al. 1999, Bouzek et al. 1998, Bouzek and Roušar 1993, Bouzek et al. 1997, De Koninck and Bélanger 2003, De Koninck et al. 2003, Hives et al. 2006, Hives et al. 2008, Hives et al. 2008, Macova et al. 2010, Toušek 1962, Venkatadri et al. 1974).

Three basic methods of ferrates(VI) preparation are reported in the literature (Macova et al. 2009). The first one is called dry oxidation or thermal method, the second one is so-called wet oxidation and the last one is an electrochemical anodic dissolution (oxidation) of iron or cast iron in the concentrated hydroxide solutions. Using electrochemical methods the high purity ferrates(VI) are prepared (Macova et al. 2009, Sharma 2002). However, even a small amount of water presented in the highly alkaline paste decomposes ferrate(VI) within hours.

To minimize disadvantages of previous aqueous approach an electrochemical treatment of iron in low-temperature melts binary hydroxide systems has been proposed (Hives et al. 2006). The major advantage of this treatment is, usually, the negli- 
gible presence of water. Another advantage of this technology is the fact that the reaction rate can be easily and continuously controlled by adjusting temperature and potential in order to achieve the optimum anodic dissolution conditions. Ferrates(VI) are easily detected by observing the colour change of the electrolyte during electrolysis. Titration, chemical precipitation and UV-Vis spectroscopy methods are used for the quantitative determination of ferrates(VI) concentration (Delaude and Laszlo 1996, Licht et al. 2001, Licht et al. 2001).

The main goal of this work was to study the stability of electrochemically prepared ferrates(VI) by transpassive oxidation in molten sodium hydroxide at relatively low temperatures in order to optimize preparation process for further utilization of ferrates(VI) in waste water treatment.

\section{Experimental}

Sodium hydroxide (p.a., Mikrochem Ltd. Pezinok, Slovakia) was used for electrolyte preparation. An oil thermostat JULABO (Germany) with calibrated sensor, stainless steel box and PTFE crucible with the sample was utilized for our experiments. Reference connection of thermocouple was immersed in a Dewar flask filled with ice-water and measuring connection was immersed into the melt at the same level as electrodes (Hrnčiariková et al. 2010).

Electrochemical measurements were performed using AUTOLAB instrument PGSTAT 20 (ECO Chemie, The Netherlands). Five working electrodes (WE) were made from pure iron (Fe) (99.95\% (w/w) Fe, $0.005 \%$ (w/w) C, $0.0048 \%(w / w) ~ N i$ and $0.0003 \%(\mathrm{w} / \mathrm{w}) \mathrm{Mn})$ with total geometric area of $60 \mathrm{~cm}^{2}$. Quasi-reference electrode (RE) was made from the same material as WE. Counter electrode (CE) was made from mild steel (steel class 11). Cathodic and anodic compartments were divided by polypropylene textile-like diaphragm. Electrolysis were carried out in a PTFE crucible containing $200 \mathrm{~g}$ of melt (100 g of anolyte) (NaOH:NaOH. $\left.\mathrm{H}_{2} \mathrm{O}\right)$ at $80{ }^{\circ} \mathrm{C}, 3.5 \mathrm{~V}$ and $25 \mathrm{~mA} \mathrm{~cm}^{-2}$.

The amount of ferrates(VI) in the sample were determined by UV-Vis spectrometry at $\lambda=505 \mathrm{~nm}$. Each solidified sample was prior to analysis dissolved in $\mathrm{NaOH}$ solution in ultrasonic bath. Calibration curve were constructed by measuring an absorbance of various concentrations of commercial $\mathrm{K}_{2} \mathrm{FeO}_{4}(98 \%$, Sigma-Aldrich) in $13 \mathrm{M}$ $\mathrm{NaOH}$. Samples were stable for at least one hour. Each measurement was repeated three times.

\section{Results and discussion}

The aim of this contribution was to study the stability of ferrates(VI) in molten $\mathrm{NaOH}: \mathrm{NaOH}$. $\mathrm{H}_{2} \mathrm{O}$ mixture during and after the galvanostatic electrolysis at $80^{\circ} \mathrm{C}$.

Current efficiency, $\eta$, of the overall electrolysis time, $\tau_{\mathrm{el}}$ is illustrated in the next Fig. 1.

One can see that the current efficiency slightly decreases during electrolysis. It may be connected with the formation of protective passive layer at the electrode surface during electrochemical treatment as it was observed previously (Hrnčiariková et al.

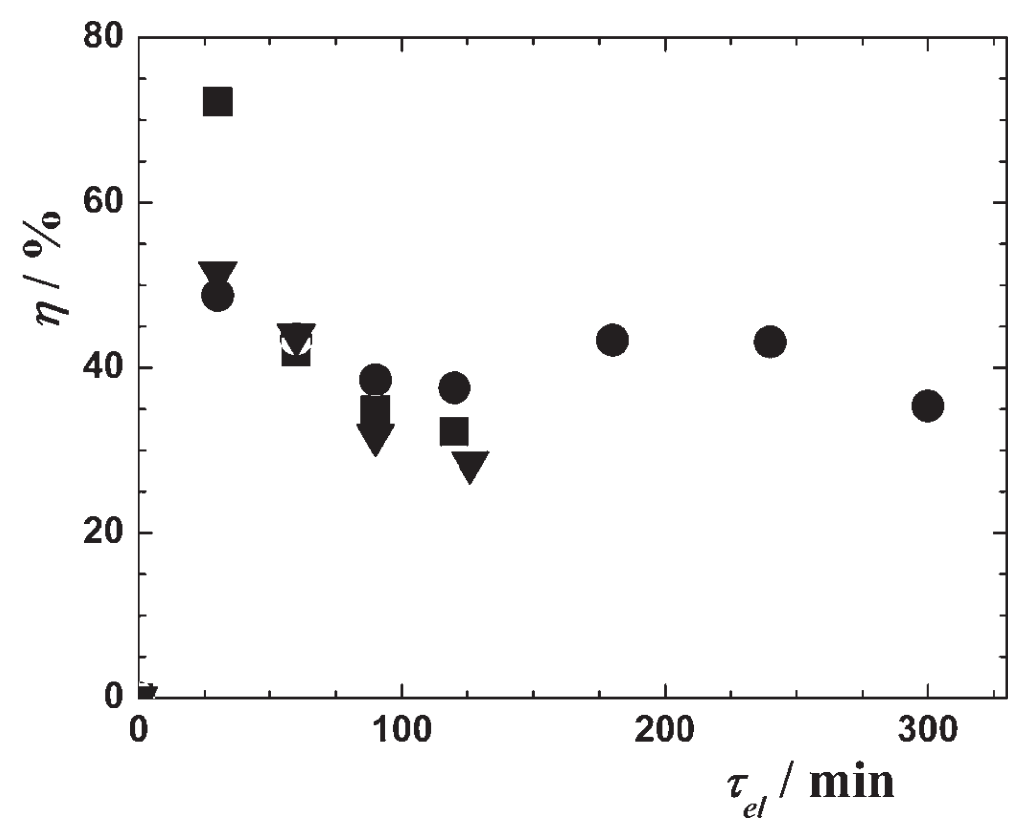

Fig. 1. Dependence of the current efficiency (\%) on the time of the electrolysis. Electrolysis duration, $\tau_{\mathrm{el}}$ : $120 \mathrm{~min}$; $126 \mathrm{~min}$; $300 \mathrm{~min}$. 
2013, Hrnčiariková et al. 2010, Hrnciarikova et al. 2013). After certain electrolysis time the formation and subsequent disintegration of passive layer due to the oxygen evolution and/or high potential is balanced. Therefore the plateau on the curve describing the dependence the electrolysis current efficiency against electrolysis time is reached.

In Fig. 2 the dependence of the mass fraction, $w$ of ferrates(VI) on the measuring time, $\tau$ is plotted. Measuring time means that the amount of ferrates in the system was measured not only during the electrolysis time, $\tau_{\mathrm{el}}$ but also a certain time after the current was switched off. From Fig. 2 it is clearly visible that during the electrolysis the amount of ferrates(VI) increased with time. When the current was switched off the amount of ferrates(VI) remains almost constant or slightly decreases for further tens or hundreds of minutes. The amount of ferrates(VI) in anodic compartment was not above $3 \%(\mathrm{w} / \mathrm{w})$. This is because our aim was not to prepare as much ferrates(VI) as possible but to study their stability and kinetics of their decomposition in molten hydroxide in order understand their behaviour at elevated temperatures.

Kinetics of ferrates(VI) decomposition prepared in sodium hydroxide melt and the decomposition of

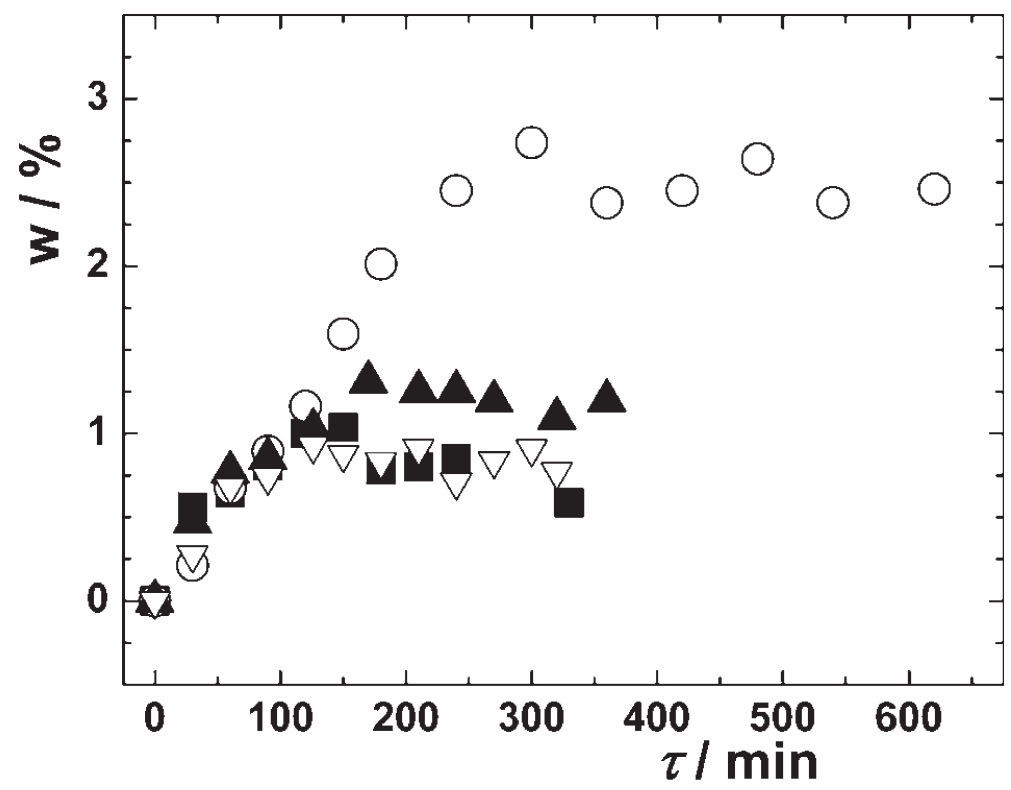

Fig. 2. Dependence of the mass fraction of ferrates(VI) on the measuring time, $\tau$. Electrolysis time, $\tau_{\mathrm{el}}: \mathbf{\square} 120 \mathrm{~min} ; \nabla 126 \mathrm{~min}$; $\Delta 170 \mathrm{~min} ; \bigcirc 300 \mathrm{~min}$.

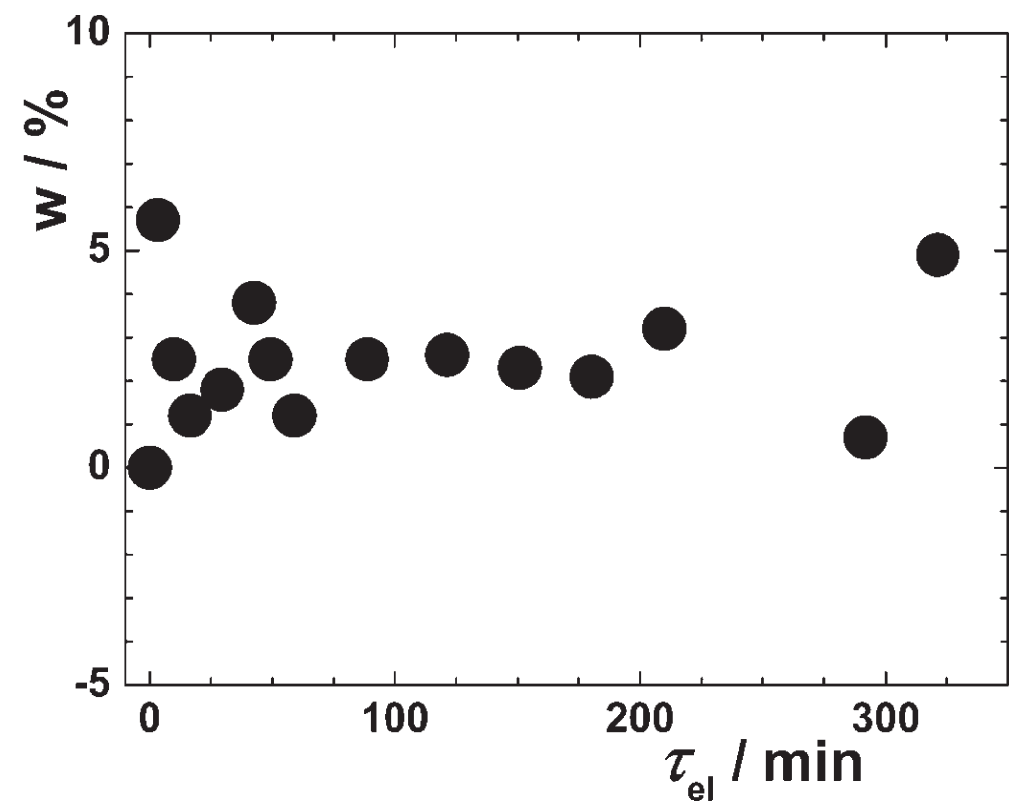

Fig. 3. Kinetics of ferrates(VI) decomposition. 
$\mathrm{K}_{2} \mathrm{FeO}_{4}$ standard in alkaline aqueous solution were compared. In this reference solution ferrates(VI) were not detectable after ca. 30 minutes. However, ferrates(VI) prepared electrochemically in molten $\mathrm{NaOH}$ environment remained stable for several hours in molten form as shown in Fig. 3.

The stability of ferrates(VI) in dried, solidified form was also checked. It was found that ferrates(VI) after solidification and cooling were stable for several months in an air-moisture free environment. These observations confirm our assumption that electrochemically prepared ferrates(VI) in molten sodium hydroxide are very stable not only in molten form (during electrolysis and/or after electrolysis) but also in dried, solidified form. It can be summarized that ferrates(VI) prepared in this way are undoubtedly suitable for utilization at waste water treatment.

\section{Acknowledgement}

The authors gratefully acknowledge the financial support for this research by the Ministry of Education, Science, Research and Sport of the Slovak Republic within project VEGA 1/0985/12 and by the Research E Development Operational Programme funded by the ERDF within project ITMS 26240220073.

\section{References}

Armstrong RD, Baurhoo I (1972) Journal of Electroanalytical Chemistry 40: 325-338.

Beck F, Kaus R, Oberst M (1985) Electrochimica Acta 30: 173-183.

Bouzek K, Flower L, Roušar I, Wragg AA (1999) Journal of Applied Electrochemistry 29: 569-576.

Bouzek K, Lipovská M, Schmidt M, Roušar I, Wragg AA (1998) Electrochimica Acta 44: 547-557.

Bouzek K, Roušar I (1993) Journal of Applied Electrochemistry 23: 1317-1322.

Bouzek K, Roušar I, Bergmann H, Hertwig K (1997) Journal of Electroanalytical Chemistry 425: 125-137.

Bouzek K, Schmidt MJ, Wragg AA (1999) Electrochemistry Communications 1: 370-374.

De Koninck M, Bélanger D (2003) Electrochimica Acta 48: $1435-1442$.

De Koninck M, Brousse T, Bélanger D (2003) Electrochimica Acta 48: 1425-1433.

Delaude L, Laszlo P (1996) Journal of Organic Chemistry 61: 6360-6370.

Denvir A, Pletcher D (1996) Journal of Applied Electrochemistry 26: 823-827.
Grube G, Gmelin H (1920) Zeitschrift für Elektrochemie und angewandte physikalische Chemie 26: 153-161.

He WC, Wang JM, Shao HB, Zhang JQ, Cao CN (2005) Electrochemistry Communications 7: 607-611.

Hives J, Benova M, Bouzek K, Sharma VK (2006) Electrochemistry Communications 8: 1737-1740.

Hives J, Benova M, Bouzek K, Sitek J, Sharma VK (2008) Electrochimica Acta 54: 203-208.

Hives J, Macova Z, Benova M, Bouzek K (2008) Journal of the Electrochemical Society 155: E113-E119.

Hrnčiariková L, Gál M, Kerekeš K, Híveš J (2013) Electrochimica Acta DOI: 10.1016/j.electacta.2013.05.144.

Hrnčiariková L, Hiveš J, Kerekeš K, Kamenár J, Gál M (2010) Acta Chimica Slovaca 3: 74-83.

Hrnciarikova L, Kerekes K, Hives J, Gal M (2013) International Journal of Electrochemical Science 8: $7768-7778$

Jiang JQ, Lloyd B (2002) Water Research 36: 1397-1408.

Jiang JQ, Wang S (2003) Environmental Engineering Science 20: 627-633.

Lapicque F, Valentin G (2002) Electrochemistry Communications 4: 764-766.

Lee Y, Um IH, Yoon J (2003) Environmental Science \& Technology 37: 5750-5756.

Licht S, Naschitz V, Halperin L, Halperin N, Lin L, Chen JJ, Ghosh S, Liu B (2001) Journal of Power Sources 101: 167-176.

Licht S, Naschitz V, Liu B, Ghosh S, Halperin N, Halperin L, Rozen D (2001) Journal of Power Sources 99: 7-14.

Licht S, Yang L, Wang BH (2005) Electrochemistry Communications 7: 931-936.

MacDonald DD, Roberts B (1978) Electrochimica Acta 23: 781-786

Macova Z, Bouzek K (2011) Journal of Applied Electrochemistry 41: 1125-1133.

Macova Z, Bouzek K (2012) Journal of Applied Electrochemistry 42: 615-626.

Macova Z, Bouzek K, Hives J, Sharma VK, Terryn RJ, Baum JC (2009) Electrochimica Acta 54: 2673-2683.

Macova Z, Bouzek K, Sharma VK (2010) Journal of Applied Electrochemistry 40: 1019-1028.

Pick W (1901) Zeitschrift für Elektrochemie 7: 713-724.

Serebrennikova I, Paramasivam I, Roy P, Wei W, Virtanen S, Schmuki P (2009) Electrochimica Acta 54: 5216-5222.

Sharma VK (2002) Advances in Environmental Research 6: $143-156$.

Sharma VK, Burnett CR, Yngard RA, Cabello DE (2005) Environmental Science \& Technology 39: 3849-3854.

Toušek J (1962) Collection of Czechoslovak Chemical Communications 27: 914-919.

Venkatadri AS, Bauer HH, Wagner WF (1974) Journal of the Electrochemical Society 121: 249-250.

Zhang H, Park S-M (1994) Journal of the Electrochemical Society 141: 718-724. 